\title{
PERANCANGAN RUANG BERMAIN DAN BERSANTAI YANG MENCIPTAKAN KEBAHAGIAAN
}

\author{
Illona Delarosa Widjaja1), Franky Liauw ${ }^{2)}$ \\ 1)Program Studi S1 Arsitektur, Fakultas Teknik, Universitas Tarumanagara, Ilona.3155160065@stu.untar.ac.id \\ 1)Program Studi S1 Arsitektur, Fakultas Teknik, Universitas Tarumanagara, frankyl@ft.untar.ac.id \\ Masuk: 21-01-2021, revisi: 21-02-2021, diterima untuk diterbitkan: 26-03-2021
}

\begin{abstract}
Abstrak
Seiring berkembangnya zaman, rutinitas manusia akan semakin padat dan dapat menimbulkan masalah dalam hal ini emosi negatif yaitu stres dalam diri manusia. Hal ini menjadi perhatian dalam konsep berhuni di masa depan, yaitu bagaimana manusia bertahan hidup. Manusia bertahan hidup memerlukan beberapa kebutuhan. Kebutuhankebutuhan tersebut dipenuhi manusia untuk mengeluarkan emosi negatif dan mendapatkan emosi positif. Karena itulah proyek ini bertujuan untuk memenuhi rasa bahagia tersebut dengan menyuguhi program-program untuk bermain dan bersantai di waktu luang bagi masyarakat sekitar kawasan atau luar kawasan. Program-program tersebut diwujudkan dari beberapa teori dan pemahaman tentang kebahagiaan yang lalu diaplikasikan ke dalam arsitektur. Dalam hal ini, penempatan dan fungsi ruang dan juga sirkulasi diciptakan secara dinamis dan berdasarkan hierarki pada massa bangunan dengan berlandaskan tujuan untuk bermain dan bersantai. Proyek ini diharapkan agar dapat membuat pengunjung melepas stres dan merasa bahagia.
\end{abstract}

Kata kunci: bahagia; berhuni; bermain; bersantai; emosi

\begin{abstract}
As the time goes by, humans' daily activities predicted will be denser and could inflict some problems which built by negative emotion that occurs form human stress. This matter become concerned in a concept of dwelling in the future, which is how human survive. Humans in matter of survival, need some necessities. Those needs are fulfilled by human for releasing any negative emotions and gainning positive emotions or happiness. Therefore, this project is intended to fulfill happiness by proposing programs for playing and relaxing in leisure time for people around or outside the area. Those programs are based by some theories and understandings about happiness and which are being applied into architecture. In this case, placing and function of the space and also circulation are being thought out dynamically and based on hierarchy on the mass with the point of interest in playing and relaxing. This project is hoped for visitors who are coming could release stress and feeling happy.
\end{abstract}

Keywords: dwelling; emotion; happiness; play; relaxing

\section{PENDAHULUAN}

\section{Latar Belakang}

Peradaban manusia akan semakin maju seiring dengan perkembangan zaman yang akan berakibat rutinitas manusia akan semakin padat. Keadaan ini kemudian menyebabkan munculnya emosi negatif seperti stress, yang perlu menjadi perhatian dalam konsep berhuni di masa depan. Berhuni mempunyai banyak arti, salah satunya ialah bertahan hidup yang merupakan tujuan manusia dalam menjalani kehidupannya. Manusia dalam bertahan hidup memerlukan beberapa kebutuhan. Manusia terlahir dengan berbagai macam kebutuhan dalam hidupnya. Abraham Maslow menyatakan bahwa setiap manusia memiliki lima kebutuhan dasar yaitu: kebutuhan fisiologis, keamanan ( fisik dan psikologis ), cinta, harga diri, dan aktualisasi diri (Maslow,1984). Manusia memiliki kebutuhan dasar yang bersifat heterogen. Setiap orang pada 
dasarnya memiliki kebutuhan yang sama, akan tetapi karena budaya, maka kebutuhan tersebut juga ikut berbeda. Dalam memenuhi kebutuhan manusia menyesuaikan diri dengan prioritas yang ada.

Dalam kebutuhan-kebutuhan tersebut, manusia ingin mencapai kehidupan yang bermakna dalam hidupnya. Menurut Bastaman, hidup bermakna adalah gerbang menuju kebahagiaan. Itu adalah corak kehidupan yang menyenangkan, penuh semangat, bergairah, serta jauh dari rasa cemas dan hampa dalam menjalani kehidupan sehari-hari (Bastaman, 2007). Keseharian manusia yang semakin padat tersebut memicu stressor negatif pada manusia yang dapat menyebabkan stres dan juga membuat secara tidak langsung waktu luang manusia berkurang untuk beristirahat maupun melakukan kegiatan yang membuat mereka senang. Hal ini membuat manusia biasanya mencari kegiatan yang dapat membuat mereka melupakan rasa tertekan tersebut dengan meluangkan waktu untuk melakukan kegiatan yang menyenangkan. Maka dari itu proyek ini menyuguhkan program-program sebagai wadah kegiatan relaksasi dan bermain yang dapat dijadikan kegiatan dalam waktu luang. Proyek ini diharapkan dapat membantu manusia untuk mengeluarkan emosi negatif dan mendapatkan emosi positif berupa rasa bahagia.

\section{Rumusan Permasalahan}

Yang menjadi fokus masalah utama dalam penelitian proyek ini adalah:

a. Bagaimana proyek yang diajukan dapat memenuhi kebutuhan akan dwelling di masa depan terkait dengan waktu luang dan kebahagiaan?

b. Bagaimana peran arsitektur dalam berhuni yang mampu memberikan rasa bahagia ?

\section{Tujuan}

a. Menghadirkan program arsitektur yang interaktif untuk berhuni dalam menghadapi rasa stres dan meningkatkan rasa bahagia.

b. Mendorong munculnya pengalaman yang menyenangkan terkait dengan situasi dan kondisi apapun dalam berhuni untuk mencapai kebahagiaan.

c. Membantu menurunkan tingkat stres masyarakat di Ibu Kota Jakarta terutama pada kawasan dengan produktifitas yang tinggi.

\section{KAJIAN LITERATUR}

\section{Dwelling}

Menurut para ahli :

a. Christian Norberg-Schulz - The Concept of Dwelling

Dalam buku The Concept Of Dwelling (Norberg-Schulz,1985) dwelling memiliki arti lebih dari memiliki atap di atas kepala, yaitu :

a. Space : Mode kolektif, adanya pertemuan dengan manusia lain untuk melakukan pertukaran, baik itu produk, gagasan atau perasaan untuk merasakan pengalaman hidup sebanyak dan seberagam mungkin

b. Society value : Mode publik, adanya kesepakatan dengan manusia lain untuk menerima nilainilai umum

c. Yourself, Your Own World: Mode privat, menjadi diri sendiri dengan memiliki dunia kecil kita sendiri

Dwelling di sini merujuk pada kegiatan aktif manusia (vita activa) dalam ruang daur hidup yang luas atau terbatas, seperti bekerja dan lainnya di bawah naungan (bangunan).

b. Martin Heidegger - Building, Dwelling, Thinking

Menggunakan konsep berhuni untuk menyampaikan gagasan berada di dunia, yang melampaui gagasan kehadiran belaka, menunjukkan cara suatu entitas menunjukkan dirinya di dalam dunia. 
Dwelling pada masa dulu dan sekarang mempunyai makna yang berbeda seiring berkembangnya zaman. Dulu, dwelling diartikan sebagai kebutuhan fundamental manusia masih memiliki unsur-unsur yang dikatakan Heidegger sebagai "The Fourfold". Tujuan manusia untuk ber- $d$ welling adalah untuk memenuhi kebutuhan mereka yang paling mendasar, sebuah alasan keberadaan mereka di dunia. Makna dwelling yang dikemukakan Heidegger telah bergeser. Sekarang, orientasi manusia dalam berhuni di suatu tempat bukanlah semata-mata untuk unsur-unsur ketuhanan dan alam, akan tetapi bagaimana mereka bertahan hidup di dunia yang semakin banyak persaingan ini (Heidegger, 1971).

\section{Kebutuhan}

Abraham Maslow membagi kebutuhan dasar manusia ke dalam lima tingkat berikut:

a. Physical Needs (Kebutuhan-kebutuhan fisik) Kebutuhan fisik merupakan kebutuhan yang berhubungan dengan kondisi tubuh seperti pangan, sandang, dan papan.

b. Safety Needs (Kebutuhan-kebutuhan rasa aman) Kebutuhan ini lebih bersifat psikologi individu dalam kehidupan sehari-hari. Misal: perlakuan adil, pengakuan hak dan kewajiban, jaminan keamanan.

c. Social Needs (Kebutuhan-kebutuhan sosial) Kebutuhan ini juga cenderung bersifat psikologis dan sering kali berkaitan dengan kebutuhan lainnya. Misal: diakui sebagai anggota, diajak berpartisipasi, berkunjung ke tetangganya.

d. Esteem Needs (Kebutuhan-kebutuhan penghargaan) Kebutuhan ini menyangkut prestasi dan prestise individu setelah melakukan kegiatan. Misal: dihargai, dipuji, dipercaya.

e. Self Actualization (kebutuhan aktualisasi diri) Kebutuhan ini merupakan kebutuhan tertinggi dari individu dan kebutuhan ini sekaligus paling sulit dilaksanakan. Misal: mengakui pendapat orang lain, mengakui kebenaran orang lain, mengakui kesalahan orang lain dapat menyesuaikan diri dengan situasi.

\section{Kebahagiaan}

a. Terdapat emosi positif dan emosi negatif. Emosi negatif tergambarkan oleh perasaan takut, sedih, marah, ketidaksukaan dan perasaan negatif lainnya, sedangkan emosi positif adalah sebaliknya. Salah satu bentuk emosi positif ialah kebahagiaan (Seligman, 2005)

b. Kebahagiaan berasal dari kata bahagia yang berarti feeling good, having fun, having a good time, atau sesuatu yang membuat pengalaman menjadi menyenangkan (Adler, 2003)

c. Kebahagiaan merupakan sebongkahan perasaan yang dapat dirasakan berupa perasaan senang, tentram, dan memiliki kedamaian (Rusydi, 2007)

\section{Perilaku yang Menjadi Sumber Kebahagiaan}

Dalam bukunya yang berjudul Bahagia, Kenapa Tidak?, Wattimena (2015)mengungkapkan beberapa perilaku yang menjadi sumber kebahagiaan:

a. Mencoba hal baru : Dalam mencoba hal baru terdapat kepuasan, di mana seseorang dengan mencoba hal baru dalam banyak kesempatan bisa menemukan suasana baru, unik dan menyenangkan

b. Keterbukaan : merupakan karakter peradaban yang maju bagi manusia, bekerja dalam meningkatkan pengetahuan dan mengembangkan pengalaman serta mengenal karakter orang lain dengan berbagai kebudayaan.

c. Hubungan yang harmonis : perilaku sosial dan individual yang positif

d. Self-challenge : menyukai tantangan lahir dari keberanian dan dan pantang mundur yang dimiliki seseorang. Orang yang memiliki karakter pantang mundur pasti juga mempunyai keinginan.

e. Perawakan ceria : wajah ceria penuh senyuman adalah gambaran setiap wajah bercahaya, menyenangkan dan indah. Dan sebaliknya, wajah cemberut kedua alisnya mengkerut adalah gambaran wajah seseorang yang resah dan dirundung kesedihan. 


\section{Ketidakbahagiaan}

Ketidakbahagiaan bisa diartikan sebagai keadaan permanen dari ketidakpuasan, selalu fokus pada apa yang tidak dimiliki, bukan apa yang sudah dimiliki saat ini. Saat kebahagiaan gagal diraih, hal ini mulai mempengaruhi kualitas keseluruhan hidup, seperti karier, hubungan asmara, dan kesejahteraan hidup. Ketidakbahagiaan dapat dihubungkan dengan stres karena perasaan tidak puas serta tidak bersyukur secara tidak langsung menuntun individu kepada tekanan yaitu tuntutan lebih besar daripada kemampuan individu untuk beradaptasi.

\section{Stres}

Dalam buku Stress Appraisal and Coping (Folkman dan Lazarus, 1984) menjelaskan stres sebagai kondisi individu yang dipengaruhi oleh lingkungan. Kondisi stres terjadi karena ketidakseimbangan antara tekanan yang dihadapi individu dan kemampuan untuk menghadapi tekanan tersebut.

\section{Waktu luang}

Waktu luang biasa disebut leisure. Leisure berasal dari kata latin licere yang berarti diizinkan (to be permitted) atau menjadi bebas (to be free). Dalam bukunya Recreation, Planning and Design (Gold, 1980), disebutkan bahwa dalam satu hari terdapat tiga penggunaan waktu yaitu :

a. Subsistance Time : waktu yang digunakan untuk melakukan kebutuhan hidup sehari-hari seperti makan, minum, tidur, dan lainnya.

b. Existance Time : waktu yang digunakan untuk melakukan pekerjaan yang berhubungan dengan profesi seperti bekerja atau belajar.

c. Leisure Time : waktu yang digunakan untuk melakukan aktivitas di luar aktivitas existance dan subsistence.

\section{Kegiatan Waktu Luang}

Berdasarkan definisi, waktu luang merupakan waktu yang digunakan untuk melakukan berbagai macam aktivitas baik untuk beristirahat, menghibur diri setelah melepas diri dari segala pekerjaan rutinnya yang padat. Beberapa kegiatan yang untuk mengisi waktu luang diantaranya: a. Kegiatan Relaksasi

Menurut Soetarlinah Sukadji (Triatmoko, 2007) relaksasi terbagi menjadi dua macam yaitu relaksasi aktif dan pasif.

- Relaksasi Aktif

Melakukan kegiatan yang bersifat produktif, cenderung meningkatkan ketrampilan harga diri. Contoh : kursus memasak

- Relaksasi Pasif

Kegiatan yang melibatkan sedikit indra. Contoh: menonton mendengarkan music, membaca buku, dan lain-lain.

b. Kegiatan Hiburan

Menurut Fine, Mortimer dan Robert (Blewitt dan Broderick, 2006) kegiatan relaksasi dapat meningkatkan ketrampilan seperti olahraga, hobi, dan kesenian atau yang lebih umum seperti bermain, melamun, nongkrong dengan teman-teman dan orang lain.

\section{METODE}

Metode yang digunakan adalah metode pembahasan secara deskriptif dengan mengidentifikasi data-data dan teori terkait yang bersifat kualitatif dan kuantitatif yang lalu dianalisa untuk memperoleh program dasar dengan peluang kombinasi dari program dasar tersebut.

Pengumpulan data dilakukan dengan cara:

a. Studi literatur terkait dengan teori dan data

b. Studi preseden, dengan membedah rancangan-rancangan yang telah terbangun yang memiliki kemiripan program pada proyek yang diajukan. 


\section{DISKUSI DAN HASIL}

\section{Ide Perancangan}

Tema pada proyek ini adalah "The Future of Dwelling based on Today". Dwelling itu sendiri mempunyai arti to survive. Manusia dalam usahanya untuk bertahan hidup memerlukan kebutuhan-kebutuhan tertentu yang bertujuan untuk mencapai kebahagiaan. Oleh karena itu pada proyek ini, arsitektur berusaha untuk memenuhi kebutuhan-kebutuhan manusia tersebut agar manusia yang berhuni di dalamnya dapat meluangkan waktu dan merasakan bahagia dengan program-program yang diajukan.

\section{Program}

Program-program pada proyek ini mempunyai tujuan untuk menimbulkan rasa senang dan bahagia serta memicu manusia untuk tertawa.

Berikut adalah beberapa program utama yang diajukan:

- Laughter Point Hall : menonton dan atau mempertunjukkan suatu game show / attractive show yang bertujuan untuk membuat orang tertawa, senang dan bahagia (Contoh : stand up comedy dan pertunjukkan-pertunjukkan lainnya). Terletak pada bagian tengah dari bangunan sebagai pusat, tidak berdinding dan diberi void pada atap agar suara tawa dapat terpancar ke seluruh bangunan dan bahkan ke area sekitar bangunan.
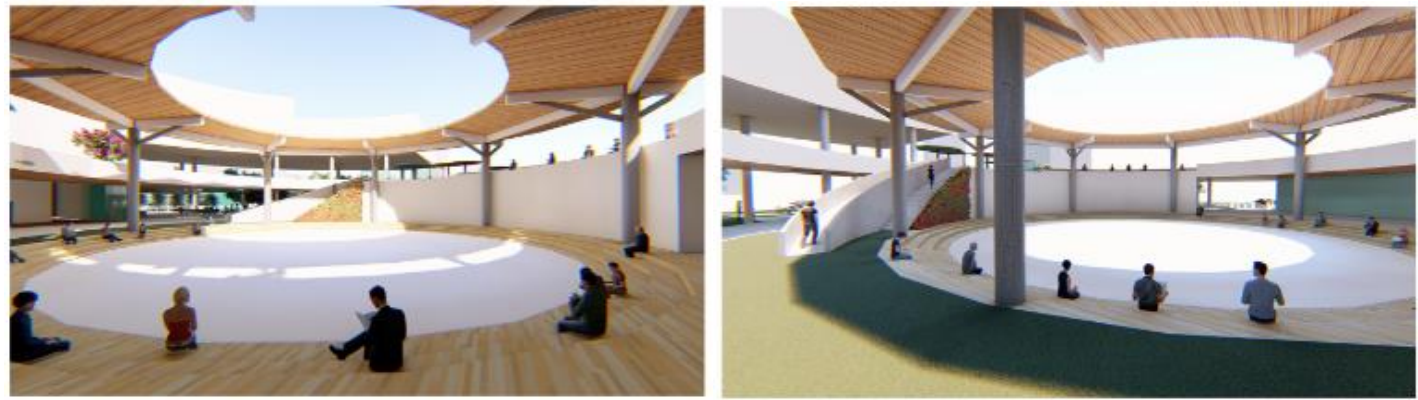

Gambar 1. Perspektif Laughter Point Hall Sumber : Penulis, 2020

- Emotion Room : terdiri dari beberapa interactive area yaitu punching, stomping, dan screaming. Ketiga hal tersebut bertujuan untuk melepaskan emosi negatif yang ada dalam diri manusia secara menyenangkan. Ruangannya terbuka tanpa diberi dinding pada sisi yang langsung terkait dengan sirkulasi agar suasana dapat terasa melegakan dan tidak tertutup.

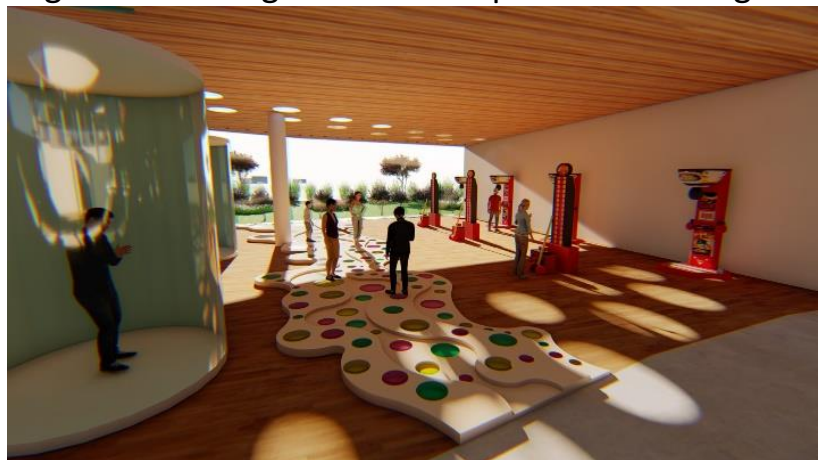

Gambar 2. Perspektif Emotion Room

Sumber : Penulis, 2020

- Light Interactive Room : Sebuah ruangan solid dengan dinding hitam lalu di dalamnya dipancarkan interactive light dari proyektor yang ada di atas langit-langit ruangan. Ditambah dengan indoor slide besar sebagai wadah bermain dan berinteraksi dengan pancaran dari proyektor. 


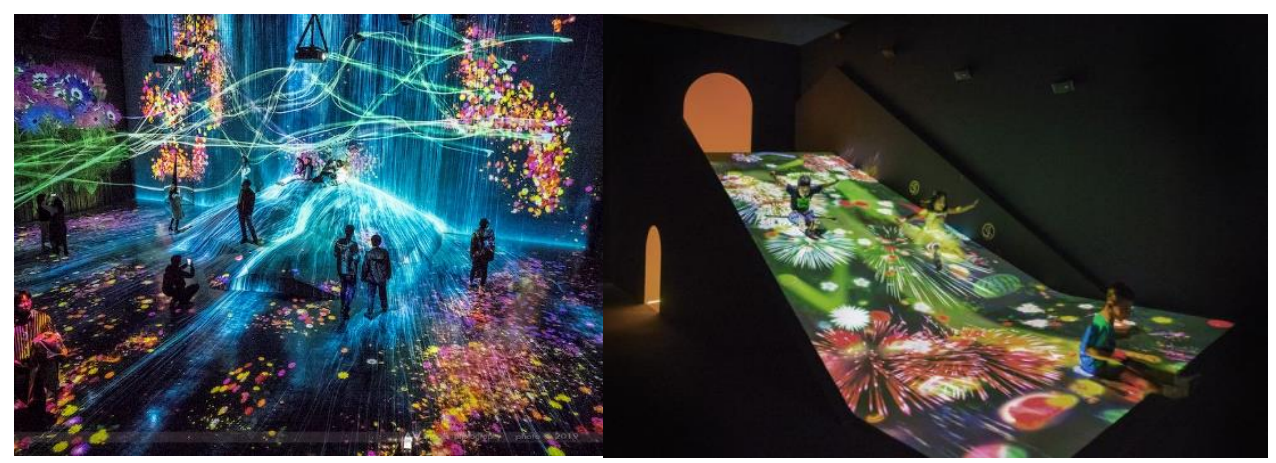

Gambar 3. Referensi untuk Light Interactive Room

Sumber : borderless.teamlab.art

- Relax Path : Ruangan untuk beristirahat dan merelaksasikan diri dengan disediakannya fish spa yang unik. Lantai diberi sentuhan menjorok ke dalam membentuk tempat duduk dan kolam kecil, lalu pada lantai sekitarnya bermaterial antislip.

- Playground : Sebuah open area yang menyediakan tempat untuk bermain bagi anak-anak maupun remaja yang tersedia di lantai satu namun tersambung dengan outdoor slide dari lantai dua yang terbuka.

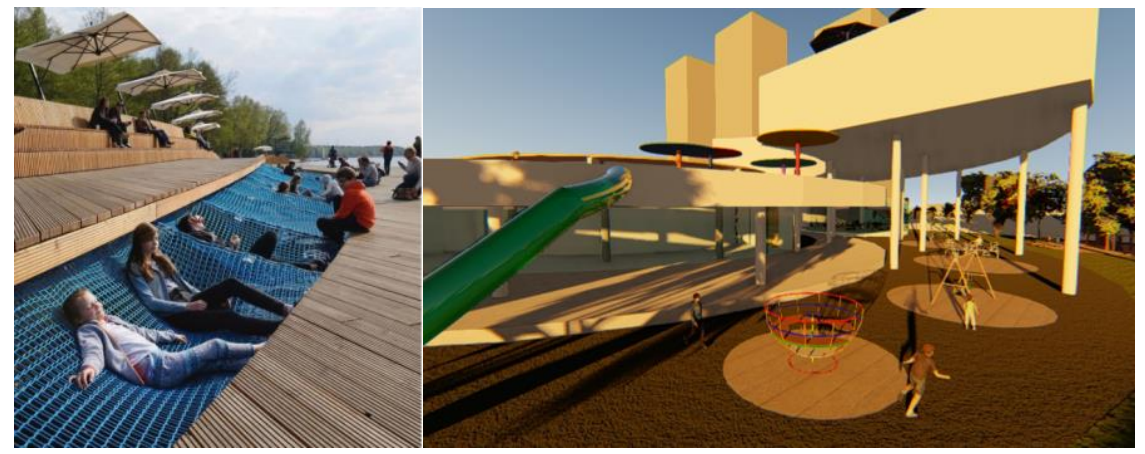

Gambar 4. Referensi net floor Sumber : archdaily
Gambar 5. perspektif playground Sumber : Penulis, 2020

- Happy Pills Room : ruangan bermain yang diwadahi dengan bola plastik besar seukuran dengan satu tubuh manusia sehingga bisa dimasuki dengan kapasitas satu orang. Bola tersebut mempunyai touch sensor dengan peil lantai di pinggi ruangan.

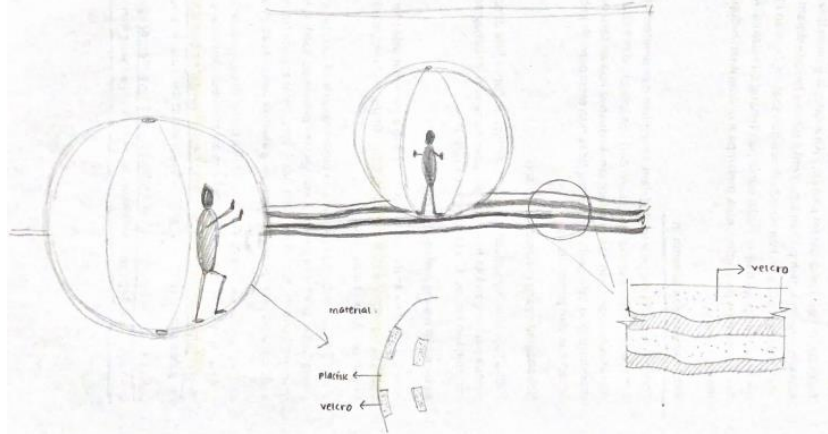

Gambar 6. Referensi Happy Pills Room

Sumber : Penulis, 2020

- Slippery Peak Room : sebuah ruangan bermain yang didesain dengan bangku penonton dan juga permainan yang melibatkan dua tim dengan disediakan permainan yang terbuat dari material plastik dan licin berundak seperti tangga. Didukung dengan kostum yang diberikan khusus untuk yang bermain. 


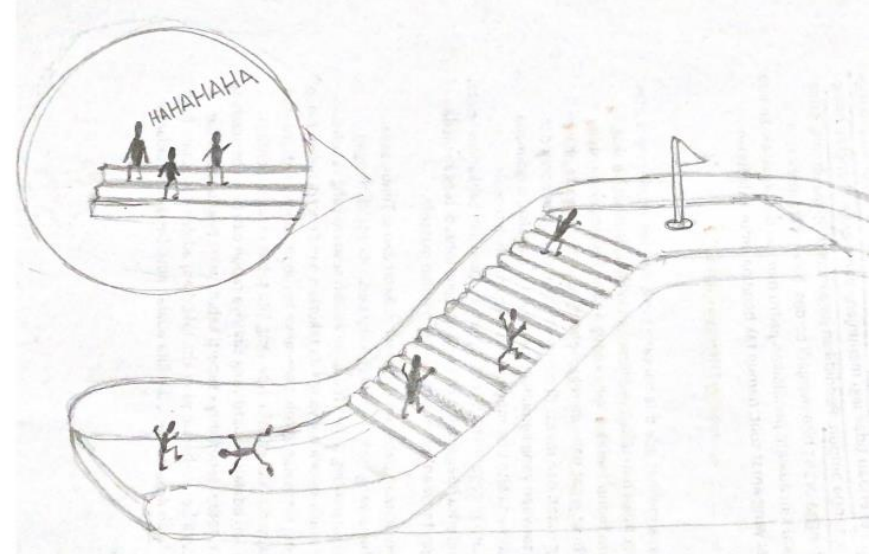

Gambar 7. Referensi Slippery Room

Sumber : Penulis, 2020

- Human Bowling Area : Outdoor area dengan disediakan pool. Konsep bermain bowling sama seperti pada umumnya namun pemain harus sliding tubuhnya agar menjatuhkan pin di ujung seberang.

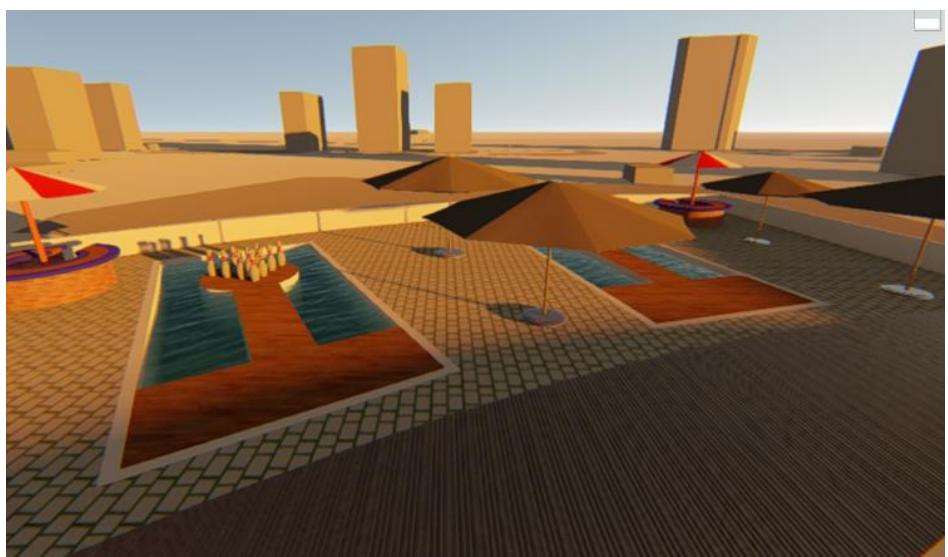

Gambar 8. Perspektif outdoor Human Bowling Area Sumber : Penulis, 2020

Ada juga beberapa program pendukung yang dibutuhkan untuk menunjang program utama yaitu :

- Lobby : area untuk menerima pengunjung dan tersedia ticketing booth untuk masuk ke dalam bangunan.

- Visual Confession Area : ruangan perantara untuk memasuki bangunan. Di sini pengunjung dapat memasuki bangunan sambil menonton atau mendengar video lucu atau suara orang tertawa.

- Reflection Room : ruangan perantara yang disediakan saat keluar dari bangunan menuju lobby. Di sini ruangan bermaterial kaca sebagai bentuk refleksi diri secara fisik bahwa pegunjung tertawa dan senang setelah memasuki bangunan proyek ini.

- Canteen : Sebuah tempat makan yang menjunjung kebersamaan. Penunjung makan dengan pengunjung lainnya. Lalu pengunjung dapat melihat secara live makanan mereka dimasak dengan keunikan ceiling yang terbuat dari kaca dan merupakan fish pond.

- Service Area : area wc, lift, dan tangga darurat. 


\section{Lokasi}

- Kawasan

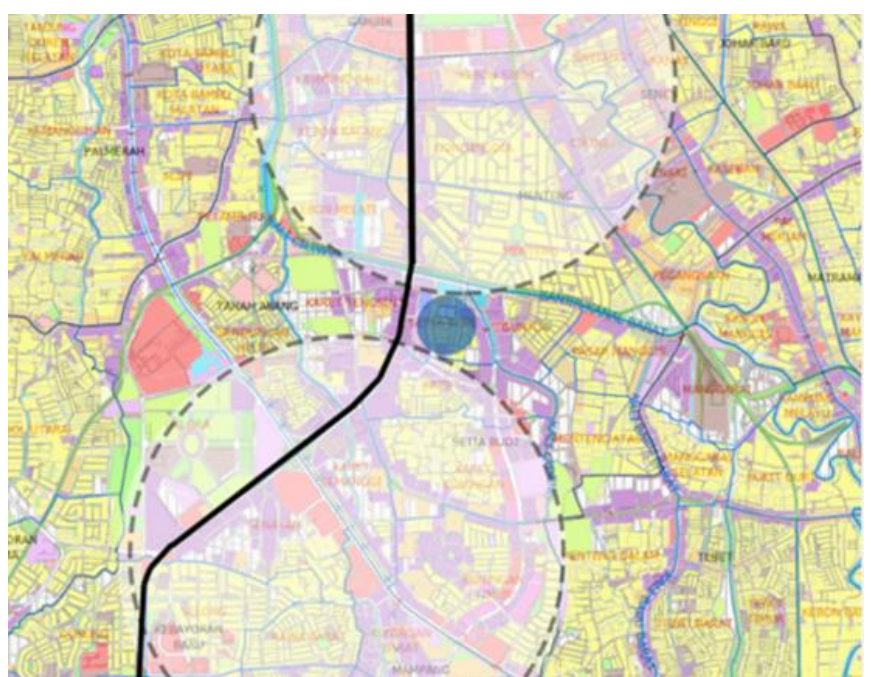

Gambar 9. Ilustrasi area Setiabudi di antara Kawasan Thamrin-Sudirman Sumber : Penulis, 2020

Kawasan yang dipilih adalah kawasan Thamrin-Sudirman karena merupakan kawasan dengan produktivitas yang tinggi, keadaan ini dapat memicu stressor pada diri seseorang dan memunculkan stressor negatif. Selain itu kawasan ini mudah dicapai oleh masyarakat sekitar kawasan maupun luar kawasan karena banyak jenis moda transportasi yang memadai, ditambah lagi kawasan ini merupakan kawasan walkable.

- Tapak

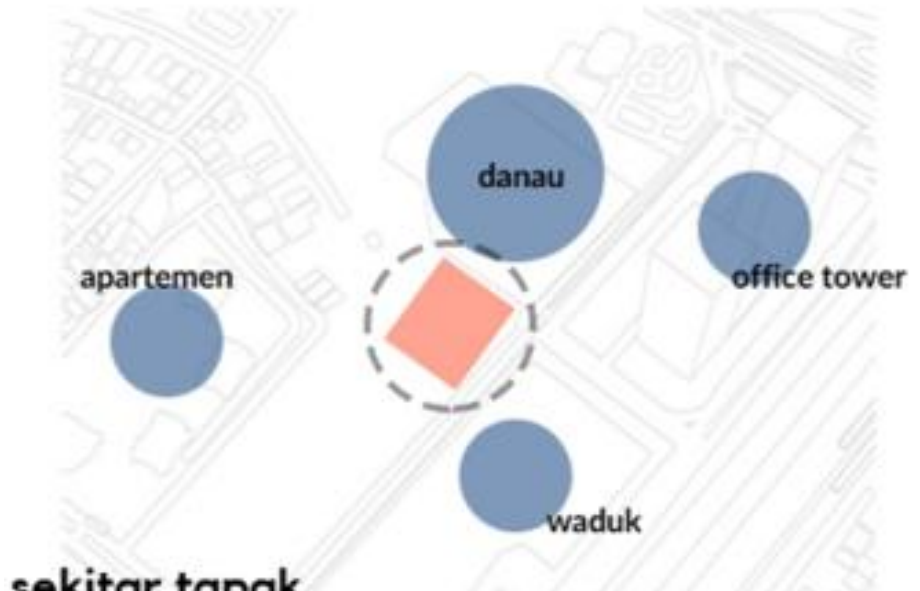

Gambar 10 : Peta Tapak dan Sekitarnya

Sumber : Penulis, 2020

Tapak dipilih pada Setiabudi karena diantara area lainnya Setiabudi perkantorannya minim, dan juga didominasi hunian yang berfungsi sebagai kost dan juga ada beberapa apartemen di sekitarnya. Selain itu kawasan Setiabudi ini terdapat danau/rawa yang bisa dijadikan sebagai view untuk proyek ini. 


\section{Massa Bangunan}

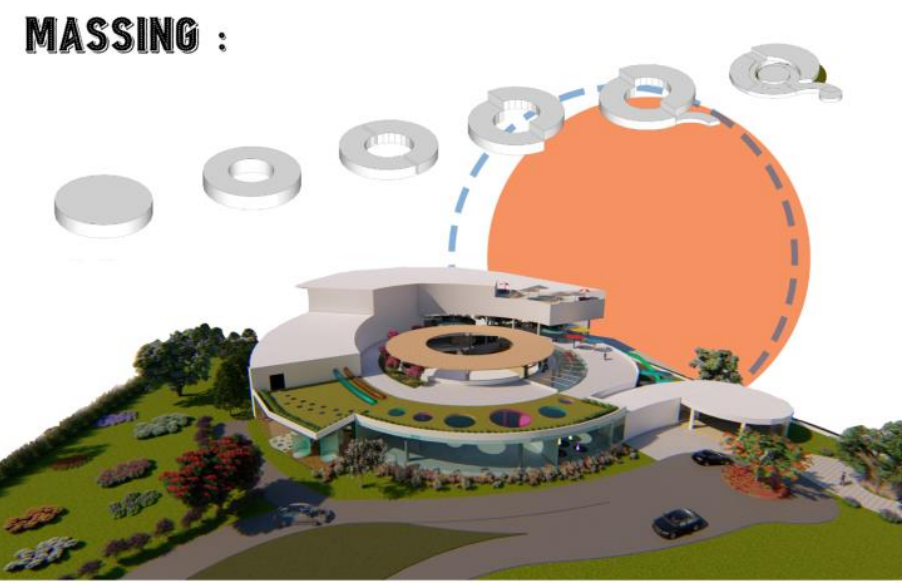

Gambar 11. Ilustrasi Proses Gubahan Massa

Sumber : Penulis, 2020

Massa bangunan berbentuk lingkaran centroid karena fungsi dari program utama yaitu Laughter Point Hall yang bertujuan untuk memancarkan suara ke seluruh penjuru bangunan dan bahkan di luar bangunan. Bangunan ini juga mempunyai banyak void dan juga menyatukan outdoor dan indoor bangunan dengan program yang disediakan.

\section{KESIMPULAN DAN SARAN}

Konsep berhuni bisa menjadi konsep yang beragam, tergantung bagaimana kita melihatnya. Berhuni pada proyek ini bertujuan untuk bertahan hidup dengan memenuhi kebutuhan manusia secara psikis yaitu mencapai kebahagiaan, tertawa dan merasa lepas dari rasa tertekan dalam mengisi waktu luangnya.

Meraih Kebahagiaan: Ruang Bermain dan Bersantai ini terletak di Jalan Setiabudi Tengah, karena tapak ini merupakan tapak di mana tidak sepadat tapak di kawasan lainnya sepanjang Thamrin-Sudirman. Tingkat keramaian minim, tetapi masih mudah digapai dengan banyak moda transportasi dan terdapat beberapa spot yang bisa dijadikan view relaksasi seperti danau/rawa.

Proyek ini merupakan sebuah pemenuhan dalam mengeluarkan emosi negatif dan menyerap emosi positif dengan cara bermain dan juga bersantai dan tidak dibatasi umur bagi pengunjung yang ingin datang karena proyek ini mengajukan berbagai macam program dari untuk anakanak hingga orang tua.

\section{REFERENSI}

Adler, M. J. (2003). Aristotle for Everybody. New York: Macmillan Publishers

Bastaman. HD, (2007). Logoterapi: Psikologi untuk Menemukan Makna Hidup dan Meraih Hidup Bermakna. Jakarta: Rajawali Pers

Blewitt \& Broderick. (2006). Kajian Pustaka: Definisi Waktu Luang. Retrieved from: https://studylibid.com/doc/956689/10-bab-ii-kajian-pustaka-a.-mengisi-waktuluang-1.-definisi

Folkman, S \& Lazarus, R.S. (1984). Stress Appraisal and Coping. New York: Springer Publishing Company.inc.

Gold, S. M. (1980). Recreation, Planning and Design. New York: Mc Graw Hill Book Company.

Heidegger, M. (1971). Building Dwelling Thinking. From Poetry, Language, Thought, translated by Albert Hofstadter. New York: Harper Colophon Books. http://home.lu.lv/ ruben/Building\%20Dwelling\%20Thinking.htm

Maslow, A. H. (1984). Motivasi dan Kepribadian: Teori Motivasi dengan Rancangan Hierarki Kebutuhan Manusia. Jakarta: PT. Gramedia 
Norberg-Schulz, C. (1985). The Concept of Dwelling: on the way to figurative architecture. New York : Rizzoli

Rusydi. (2007). Psikologi Kebahagiaan. Yogyakarta: Progresif Books.

Seligman, M.E.P. (2005). Positive Psychology: an introduction. Journal of American Psychologist Triatmoko. (2007). Mengisi Celah Waktu Luang. Retrieved from: http://popsy.wordpress.com pada tanggal 5 Juli 2010

Wattimena, R. (2015). Bahagia, Kenapa Tidak? Sebuah Refleksi Filosofis. Yogyakarta. Retrieved from : https://core.ac.uk/download/pdf/80829362.pdf 